\title{
THE QUALITY OF EDUCATION ON WORKPLACE SAFETY MASTER STUDIES - THE ISSUE OF TEACHING METHODS
}

doi: $\quad 10.2478 /$ czoto-2019-0084

Date of submission of the article to the Editor: 30/11/2018

Date of acceptance of the article by the Editor: 14/01/2019

Tomasz Nitkiewicz ${ }^{1}$ - orcid id: 0000-0003-2983-9195

Duangthida Hussadintorn Na Ayutthaya ${ }^{2}$ - orcid id: 0000-0002-1864-2808

Pisut Koomsap ${ }^{2}$ - orcid id: 0000-0002-6425-8065

Rui M. Lima ${ }^{3}$ - orcid id: 0000-0002-7991-0132

Wichai Chattinnawat ${ }^{4}$ - orcid id: 0000-0003-1936-9919

${ }^{1}$ Częstochowa University of Technology, Poland, tomasz.nitkiewicz@wz.pcz.pl

${ }^{2}$ Asian Institute of Technology, Thailand

${ }^{3}$ University of Minho, Portugal

${ }^{4}$ Chiang Mai University, Thailand

Abstract: Managing quality of education is difficult and diversified task. Certainly, at the very center of quality assurance is experience that students and graduates get throughout their education course. One of the factors influencing these experiences are teaching methods. The objective of the paper is to assess the experience of Workplace Safety and Hygiene master program students of with regard to teaching and learning methods and Industry 4.0 readiness. The objective is realized through interpretation of the survey results that was made within MSIE4.0 project among the students of different industrial engineering master programs. Additionally, the program and courses documentation is interpreted in accordance to the 'LOVE' model approach to assess education experience. The sample of the survey is based on MSc students of Workplace Safety and Hygiene that are held at Częstochowa University of Technology. As the study shows, there are some drawbacks of the program with regard to immersive approach to learning and more active students engagement. The readiness to Industry 4.0 requirements is not really visible and some purposeful actions should be made in order to make the program part of activities addressing this economic and social challenge.

Keywords: quality in higher education, work safety and hygiene program, industrial engineering, LOVE model, teaching methods

\section{INTRODUCTION}

Managing quality of education is difficult and diversified task. Certainly, at the very center of educational quality assessment is experience that students and graduates get throughout their education course. One of the factors influencing these 
experiences are teaching methods. The teaching methods consist an integral part of any studying program and, therefore, should be carefully and purposefully selected with regard to the field and scope of the program (Ulewicz, 2013). The set of methods would be different in different fields of education, no matter if we consider them on more general (humanities or science) or more detailed level (industrial engineering or management). But, some of the methods would have undoubtedly advantages that could be used in any educational field.

The focus of the paper is on Industrial Engineering (IE) education on the $2^{\text {nd }}$ level and especially on one of its fields that is Workplace Safety and Hygiene (WSH). This field of education is a type of interdisciplinary putting together technology, management, legal and health related issues. In fact, WSH master programs could significantly differ from one another, being on one hand more management and regulation oriented programs, and, on the other hand, technology oriented programs. Putting WSH program into IE category shows the intention of author to focus on its specific variant rather than definitely classifying it. Such an approach is dictated by an access to the specific programs and appropriate knowledge on them. Additionally, the participation in „Curriculum Development of Master's Degree Program in Industrial Engineering for Thailand Sustainable Smart Industry (MSIE4.0)" project (see the details in acknowledgements) has drawn attention to this issue and enabled the study. The objective of MSIE4.0 project is to develop new curriculum for master program in Industrial Engineering that meet current expectations of companies with relation to smart and sustainability priorities of Industry 4.0 (14.0) concept. Therefore, the analysis includes 14.0 perspective and presents also WSH program in this context.

\section{METHODOLOGY}

\subsection{Description of the MSc in Work Safety and Hygiene program}

As mentioned in the introduction, WSH master program could be organized in a way to fit IE field of studying. Certainly, the knowledge and competence program learning outcomes would be much different of those of mainstream IE master programs (Rui M Lima, Mesquita, Amorim, Jonker, \& Flores, 2012; Rui Manuel Lima et al., 2017) but the connection is strong enough to keep it under IE flag judging by the program criteria and content of the courses (Nitkiewicz \& Ayen, 2018). The analyzed master program in WSH is offered at Częstochowa University of Technology. It is 1,5 year program with 3 semesters with assumed availability for bachelors with engineer title after 3,5 years study. The program consists of 90 credits distributed among 19 courses (6 per semester + diploma seminar). There are 8 program courses, 5 additional courses and 12 electable courses (6 out of 12 are selected during the studies). All courses, except one project course, have a joint structure of lecture course and workshop/laboratory/project/exercise course. There are 27 program learning outcomes (PLOs) that are divide into knowledge (11), skills (11) and social competences (5). Additionally, each course has its course specific learning outcomes (CLOs) that usually are defining in 4-6 per course. For the purpose of this study course matrix and course syllabuses are analyzed.

\subsection{Explanation of LOVE model for assessment of educational experiences}

LOVE model is an assessment framework for students educational experiences that was developed on the basis of $4 \mathrm{Es}$ model. The $4 \mathrm{Es}$ model has been primarily 
designed to serve business entities to build up the competitiveness of their products and services on engaging customers and enhancing their satisfaction through this engagement (Pine \& Gilmore, 1998). The 4Es model states that the richest customer experience is stimulated once educational, entertainment, esthetic, and escapist experience are given to customers at certain times (Hussadintorn Na Ayutthaya \& Koomsap, 2017).

The idea of experience-based development of business was quickly adopted for different types of purposes and target groups. One of the most promising areas of its use is education and orientation on satisfying students with adequate learning experience. This could be achieved through the use of learning activities and methods that are encouraging students to be more active. The capacity of $4 \mathrm{Es}$ model to be used as education enhancing force has been adjusted to the specific of education through transforming it into LOVE model.

Hussadintorn Na Ayutthaya \& Koomsap (2017) proposed new four words in education context so that those four experiences can be appropriately defined and understood in education system. They are learner, observer, visitor, and experimenter (LOVE), respectively. With the new four experience words, the 4Es diagram was modified and named as LOVE model. In the 'LOVE' model, the learning experience is classified by two dimensions: student involvement (passive/active involvement), and nature of learning (absorption/immersion). The transformation process of 4Es model into LOVE model is illustrated on Fig. 1. For organizational purposes and acronym convenience, the vertical axis of $4 \mathrm{E}$ model is flipped. Additionally, higher education students and graduates are encouraged to be a researcher who gains all four types of learning experience reflected at the center in order to show possible and desired outcome of educational processes.

In order to apply LOVE model for the assessment of educational experiences it is necessary to specify the teaching and learning methods for the program and to classify them to the certain type of experiences. Table 1 explains assumed types of experiences in educational process and presents the possibilities of achieving them with regard to teaching methods. It is important to notice, that educational experience would be dependent not only on teaching method used but also on its application by teachers and perception by students. In other words, both teachers and students with their engagement (or lack of it) could affect the experience outcomes of given method and, potentially, move them to another experience category Hussadintorn $\mathrm{Na}$ Ayutthaya \& Koomsap, 2018). That shift could also happen due to hybrid approaches used by teachers that intentionally mix different methods in an attempt to get more diversified experience as an outcome. But for the sake of clarity, it is assumed that the typical outcome is achieved with methods included. 


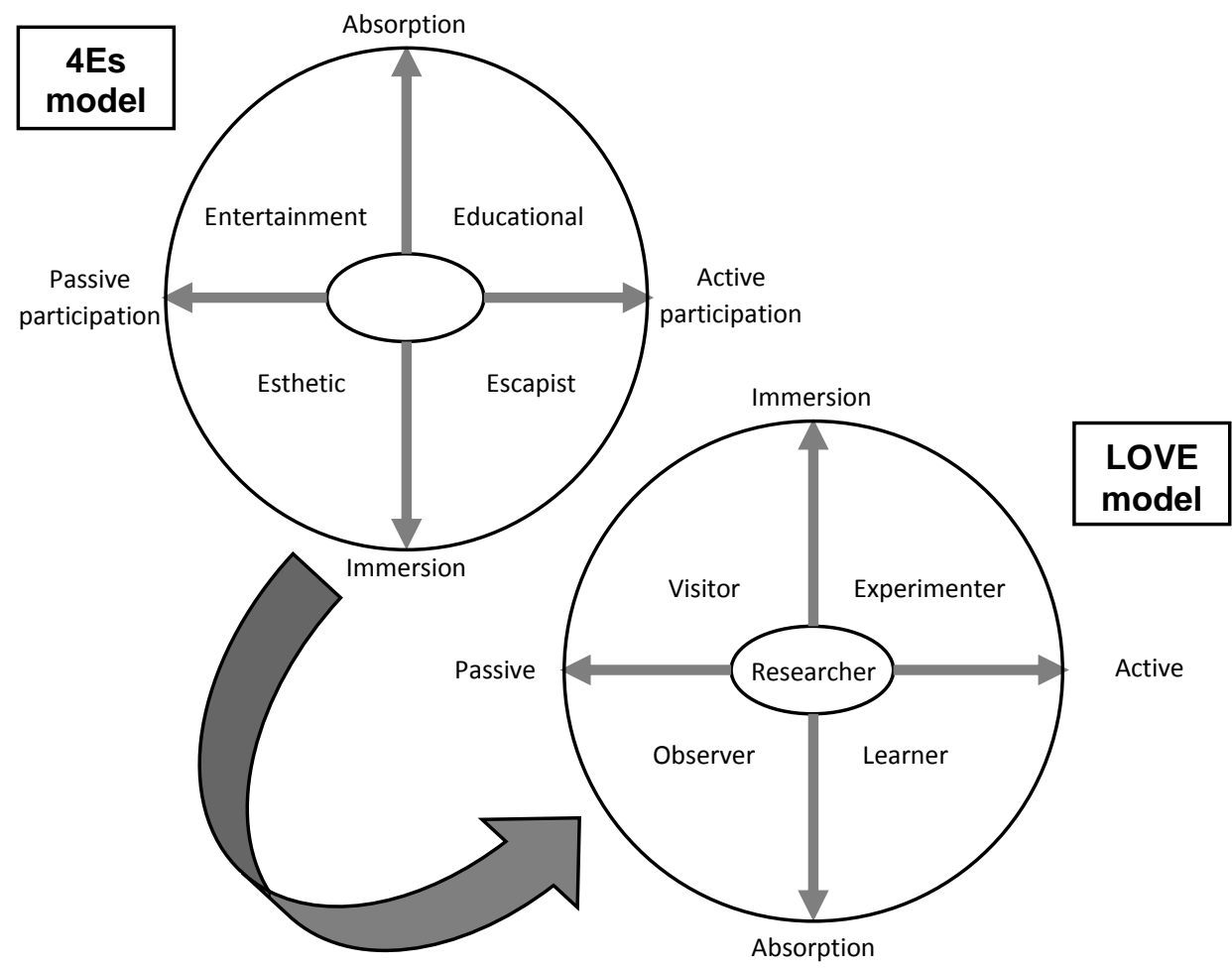

Fig. 1. Transformation of 4Es model into LOVE model

Source: based on (Hussadintorn Na Ayutthaya \& Koomsap, 2017; Pine \& Gilmore, 1998)

Table 1.

Explanation on LOVE model types of experiences and its possible applications

\begin{tabular}{|c|c|c|}
\hline $\begin{array}{c}\text { Type of } \\
\text { experience }\end{array}$ & Description & Possible application \\
\hline Learning & $\begin{array}{l}\text { This is an active aspect of experience where a } \\
\text { learner is actively absorbing information or } \\
\text { knowledge by doing something. For example, } \\
\text { taking note or actively participate in an event } \\
\text { which allows a learner to play a role of initiator } \\
\text { such as class discussion. }\end{array}$ & $\begin{array}{l}\text { Assignments } \\
\text { Case study } \\
\text { Individual presentation } \\
\text { Demonstration with exercising } \\
\text { Brainstorming } \\
\text { Problem-based learning } \\
\text { Discussion } \\
\text { Workshop } \\
\text { Class / group debate } \\
\text { Simulation } \\
\text { Game-based learning } \\
\text { Role play } \\
\text { Programmed teaching } \\
\text { Online interactive learning }\end{array}$ \\
\hline Observing & $\begin{array}{l}\text { This is a passive aspect of an experience } \\
\text { where an observer is passively absorbing } \\
\text { information or knowledge through senses. For } \\
\text { example, sitting or attending in an event which } \\
\text { limits an observer to play a role of audience } \\
\text { such as seminar or lecture. }\end{array}$ & $\begin{array}{l}\text { Lecture } \\
\text { Guided practical exercise } \\
\text { Showing video material } \\
\text { Guided conversation } \\
\text { Seminars } \\
\text { Online lecture }\end{array}$ \\
\hline Visiting & $\begin{array}{l}\text { This is a passive aspect of an experience } \\
\text { where a visitor is immersing in a real } \\
\text { experience of a subject through various } \\
\text { senses. For example, a field trip in an } \\
\text { production company gives a real atmosphere } \\
\text { of immersion in production system to visitors. }\end{array}$ & $\begin{array}{l}\text { Field class, trips and } \\
\text { excursions } \\
\text { Conference } \\
\text { Virtual simulation / tour }\end{array}$ \\
\hline
\end{tabular}




\begin{tabular}{|l|l|l|}
\hline \multirow{E}{*}{ Experimenting } & $\begin{array}{l}\text { this is an active aspect of an experience where } \\
\text { an experimenter is immersing in a real } \\
\text { experience of a subject by doing some } \\
\text { activities. To give an example through a field } \\
\text { trip in the automobile production company, the } \\
\text { experience of experimenting is given once the } \\
\text { visitors can assembly some components of a } \\
\text { car by themselves like what workers do in } \\
\text { production line. }\end{array}$ & $\begin{array}{l}\text { Project-based learning } \\
\text { Laboratory classes } \\
\text { Virtual laboratory and } \\
\text { simulation }\end{array}$ \\
\hline
\end{tabular}

Source: based on (Hussadintorn Na Ayutthaya et al., 2019)

\subsection{Survey among master students of IE related programs}

The survey was made within MSIE4.0 project on nine universities of the consortium of the project. The questionnaire was applied to their graduate students only. The number of respondents of the questionnaire consists of 450 students from Thai and EU universities. The sample included students from different master programs related to Industrial Engineering field of knowledge. Average values that are referred in the text are calculated on the whole sample, while $\mathrm{WSH}$ values relate to singled out results for $4 \%$ of surveyed students. The understanding of 14.0 concept, especially from the higher education system is not so well grounded yet. Therefore, the survey was based on several sources discussing and defining 14.0 range and scope (Hariharasudan \& Kot, 2018; Prifti, Knigge, Kienegger, \& Krcmar, 2017; Ślusarczyk, 2018; Wahlster et al., 2013; Wiśniewska-Sałek, 2018).

\section{RESULTS}

The students were questioned about the perception on their own level of understanding of specific technologies needed for Industry 4.0. The list of technologies presented to the students included the following: Sensors, Mobile, RFID, Real-time Location, Big Data, Cloud Technology, Embedded IT and M2M. Fig. 2 presents the results of the survey but from the perspective of not being prepared to use the technologies. As it could be observed WSH students are rather less prepared to Industry 4.0 technologies than its counterparts from other IE master programs. In fact, only competence level on mobile technology the same, while in all the other technologies competences are lower or much lower.

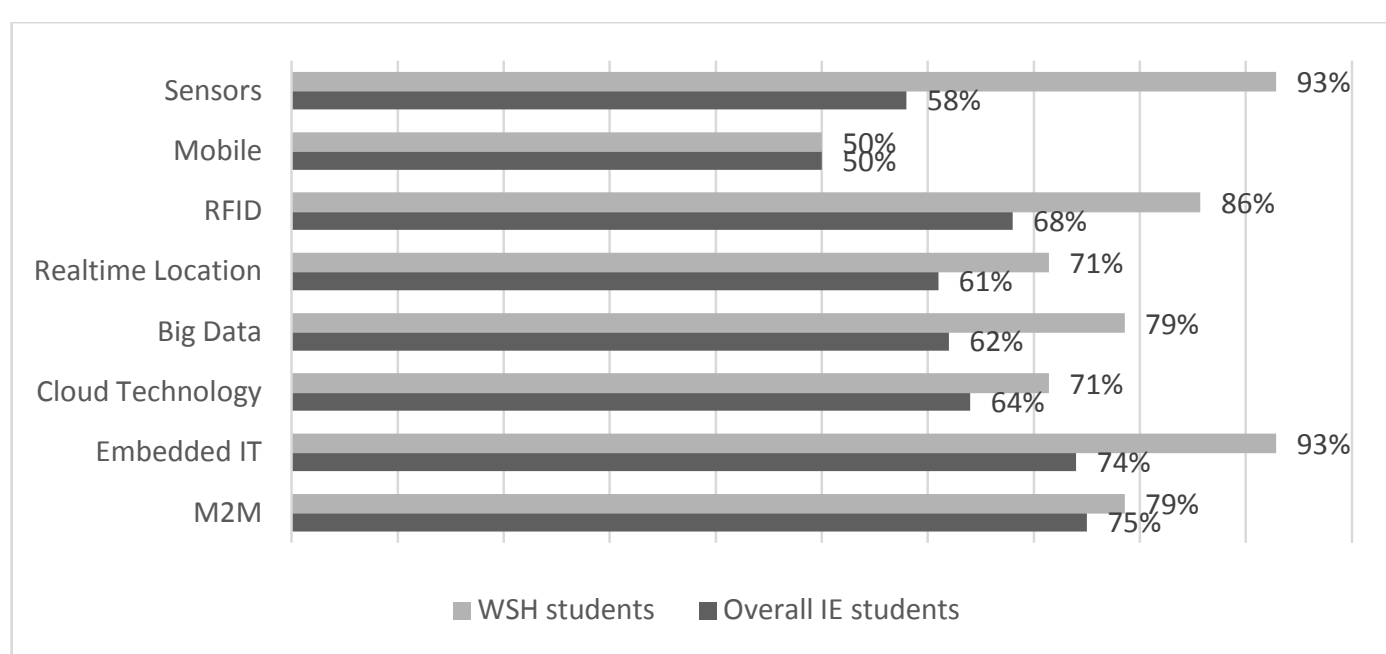

Fig. 2. Percentage of students answering “I don't have knowledge or competence" regarding specific technologies 
Students were questioned about the perception they have on their own understanding regarding several areas of knowledge and domains of application. Fig. 3 presents the results of the survey and it could be observed that all the domains of Industry 4.0 application are less covered on WSH studies than on average on all the other IE studies. Surprisingly, is also true for smart work and ergonomics issue that could have been one of the WHS curriculum elements.

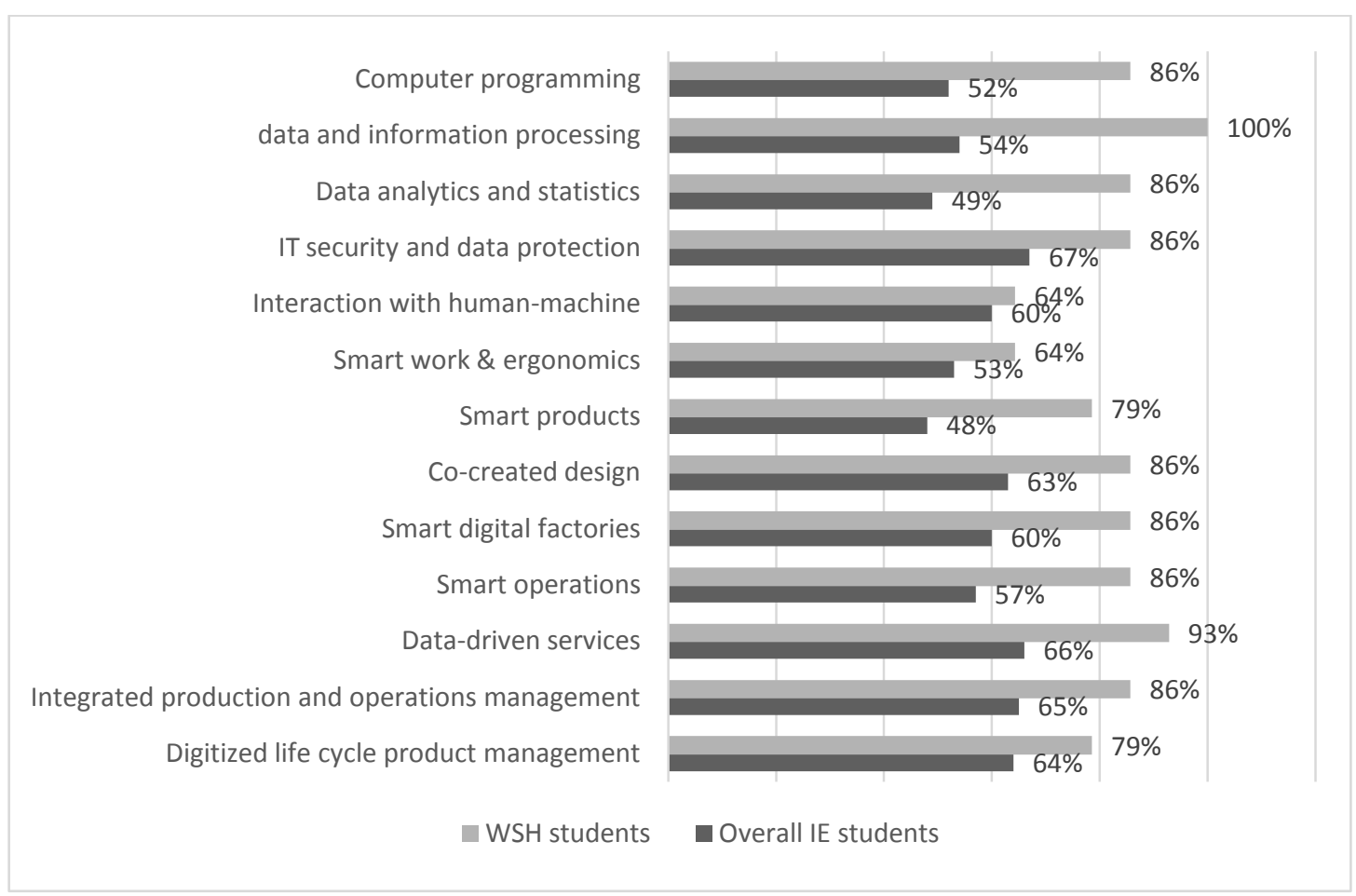

Fig. 3. Percentage of students answering "I don't have knowledge or competence" on domains of application

Before adapting LOVE model to the assessment of WHS master studies it is important to remind that the assessment is made on the program documentation and not in the participative manner. The consequence is that all the activities are classified on their occurrence in program documentation. The meaning of the above is that if any activities happen during educational course but are not declared in the documentation of the courses they are not accounted for in the analysis. This is serious limitation of the study but could not be overcome at the moment. Secondly, approach used at this point is a quantitative type of approach that includes no quality oriented assessment. Table 2 presents the results of WSH course syllabuses analysis. All the learning methods and course content are analyzed and classified to one of the possible activities as listed in LOVE model. Mentioning of an activity in course syllabus is accounted for as one occurrence. Coverage is calculated by dividing no. of occurrences by number of courses (usually one course is consisting of 2 parts, therefore, the total number with regard to this is 37 ). 
Table 2

Classification of WHS learning activities to LOVE model roles

\begin{tabular}{|c|l|c|c|}
\hline \multirow{4}{*}{ Roles } & \multicolumn{1}{|c|}{ Activities } & $\begin{array}{c}\text { No. of } \\
\text { occurences }\end{array}$ & Coverage in the program \\
\hline \multirow{5}{*}{ LEARNING } & 33 & $89,2 \%$ \\
\cline { 2 - 4 } & Assignments & 3 & $8,1 \%$ \\
\cline { 2 - 4 } & Case study & 10 & $27,0 \%$ \\
\cline { 2 - 4 } & Individual presentation & 6 & $16,2 \%$ \\
\cline { 2 - 4 } & Demonstration with exercising & 1 & $2,7 \%$ \\
\cline { 2 - 4 } & Brainstorming & 3 & $8,1 \%$ \\
\cline { 2 - 4 } & Problem-based teaching & 9 & $24,3 \%$ \\
\cline { 2 - 4 } & Discussion & 0 & $0,0 \%$ \\
\cline { 2 - 4 } & Corkshop & 5 & $13,5 \%$ \\
\cline { 2 - 4 } & Class / group debate & 2 & $5,4 \%$ \\
\cline { 2 - 4 } & Gimulation & 0 & $0,0 \%$ \\
\cline { 2 - 4 } & Rome-based learning & 2 & $5,4 \%$ \\
\cline { 2 - 4 } & Program & 0 & $0,0 \%$ \\
\cline { 2 - 4 } & Online interactive learning & 0 & $0,0 \%$ \\
\hline \multirow{5}{*}{ OBSERVING } & Lecture & 37 & $100,0 \%$ \\
\cline { 2 - 4 } & Guided practical exercise & 18 & $48,6 \%$ \\
\cline { 2 - 4 } & Showing video material & 3 & $8,1 \%$ \\
\cline { 2 - 4 } & Guided conversation & 1 & $2,7 \%$ \\
\cline { 2 - 4 } & Seminars & 2 & $5,4 \%$ \\
\cline { 2 - 4 } & Online lecture & 1 & $0,0 \%$ \\
\hline \multirow{5}{*}{ VISITING } & Field class, trips and excursions & 2 & $2,7 \%$ \\
\cline { 2 - 4 } & Conference & 0 & $5,4 \%$ \\
\cline { 2 - 4 } & Virtual simulation / tour & 14 & $0,0 \%$ \\
\hline \multirow{2}{*}{ EXPERI- } & Project-based learning & 7 & $37,8 \%$ \\
\cline { 2 - 4 } MENTING & Laboratory classes & 0 & $18,9 \%$ \\
\cline { 2 - 4 } & Virtual laboratory and simulation & & $0,0 \%$ \\
\hline
\end{tabular}

\section{CONCLUSION}

Analyzed WHS master program seem to be based on rather classical higher education model that is packed up with lectures (passive) and task / assignments (active) as teaching methods. Students role as a learner, besides assignments, is supplemented with individual presentations, discussions and class debates, demonstration and some other activities that make educational experience more diversified. Student as observer is engaged in lectures and exercises mostly, with some attention to video lecturing and seminars. Visiting has the lowest coverage and includes only single industry visit and 2 student enabled conferences throughout the studying course. It is important to notice that the conferences are not obligatory part of educational process and usually only few students decide to actively participate in them with papers, posters or presentation. Passive participation is not registered so it is not possible to assess its scale. As a part of IE group of studying fields WSH program has a decent number of project-based activities and laboratory classes. Fig. 4 summarizes the results with reference to students roles, as well as with reference to nature of students involvement and studying. Relatively low coverage of experimenting and visiting effect in reducing immersive way of experiencing education. In other words, practically oriented studying program of WSH has quite low coverage for activities based on practice. Instead, most of the knowledge is absorbed by the student that is happening through rather teacher oriented learning. Still, big share of learning activities saves the advantage of active over passive learning and in the graduation perspective guarantees the possession of learning related skills. 

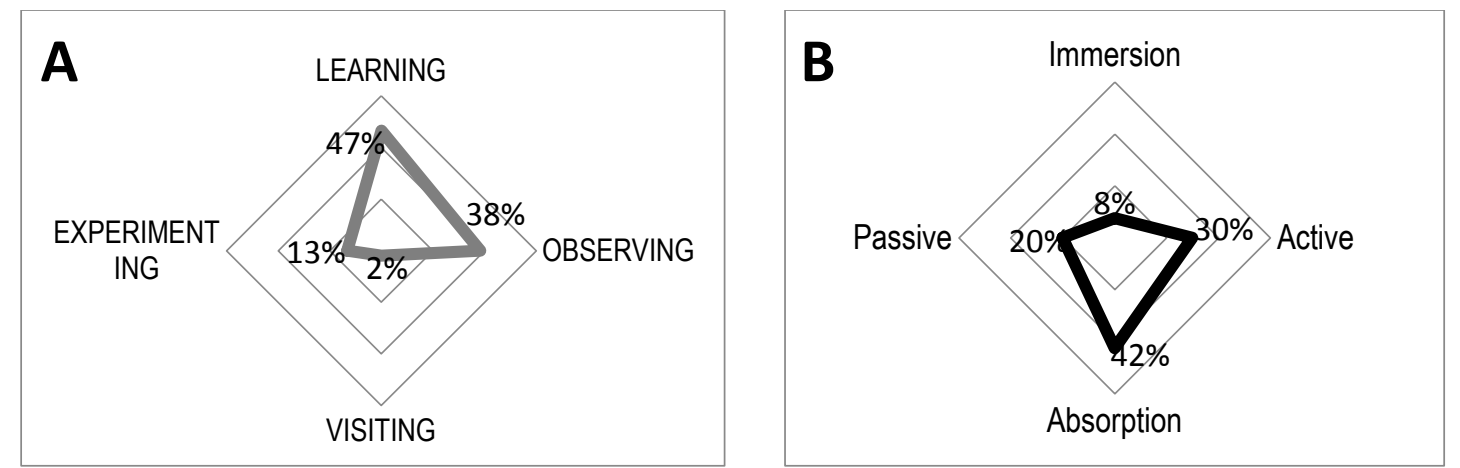

Fig. 4. Average assessment of WSH master program with reference to roles $(A)$ and student involvement / nature of learning $(B)$

The results of the study need to be supplemented with qualitative and participative methods in order to give a full picture of WSH master program. For the moment, we are justified to say that the program is missing some important factors to enhance student educational experience. Certainly, such a practical studying program should be more filled up with visiting and experimenting related activities. Through that, the immersive learning process could be stimulated and it would move learning experience more towards tring LOVE experience. Secondly, the management of educational process should be also addressed. The documentation of WSH program that was analyzed has very limited space for teaching and learning methods description. In fact, it is more concerned about the content, course structures and learning outcomes. Since the teaching methods have crucial impact on education quality they should also have appropriate coverage in course description and syllabuses. This could be done through relating them to the evaluation scheme section that has no direct and default reference to studying activities. Re-designing course syllabus form in a way that two separate sections, namely teaching methods and evaluation framework, would be joined would certainly help to track the experience building activities. And it would not only help researchers on the issue but also teachers, universities and students to consciously develop, design and select their educational experiences. Finally, there seems to be a big gap between actual WSH program and expectations and possible labor market requirements related to 14.0 concept implementation. As shown in the results of the survey, despite high share of actively engaging teaching methods, 14.0 related technologies and domains of applications are not even close to be covered. WSH education needs a complete shift that would combine content and methods mutual upgrade and some serious cooperation with industries leading the revolution.

\section{ACKNOWLEDGEMENTS}

This publication is a partial outcome of project "Curriculum Development of Master's Degree Program in Industrial Engineering for Thailand Sustainable Smart Industry (MSIE4.0)" that has been funded with support from the European Commission (Project Number: 586137-EPP-1-2017-1-TH-EPPKA2-CBHE-JP).

This publication reflects the views only of the authors, and the Commission cannot be held responsible for any use which may be made of the information contained

Co-funded by the therein. 


\section{REFERENCES}

Hariharasudan, A., Kot, S. (2018). A scoping review on Digital English and Education 4.0 for Industry 4.0. Social Sciences, 7(11), 0-13. http://doi.org/10.3390/socsci7110227

Hussadintorn Na Ayutthaya, D., \& Koomsap, P. (2017). ASSESSMENT OF STUDENT LEARNING EXPERIENCE WITH 'LOVE'. In Proceedings of INTED2017 Conference 6th-8th March 2017, Valencia, Spain (pp. 1973-1982).

Hussadintorn Na Ayutthaya, D., Koomsap, P. (2018). An Application of 'LOVE' Model for Assessing Research Experience. In M. Peruzzini (Ed.), Transdisciplinary Engineering Methods for Social Innovation of Industry 4.0 (pp. 712-720). http://doi.org/10.3233/978-1-61499-898-3-712

Hussadintorn Na Ayutthaya, D., Koomsap, P., Lima, R.M., \& Nitkiewicz, T. (2019). LEARNING EXPERIENCE FROM TEACHING AND LEARNING METHODS IN ENGINEERING EDUCATION: INSTRUCTOR VIEWPOINT (To be appeared In Proceedings of INTED2019 Conference 11th-13th March 2019, Valencia, Spain.

Lima, R. M., Mesquita, D., Amorim, M., Jonker, G., \& Flores, M. A. (2012). An Analysis of Knowledge Areas in Industrial Engineering and Management Curriculum. International Journal of Industrial Engineering and Management (IJIEM), 3(2), 75-82. Retrieved from http://

Lima, R. M., Mesquita, D., Rocha, C., Rabelo, M., Lima, R. M., Mesquita, D., ... Rabelo, M. (2017). Defining the Industrial and Engineering Management Professional Profile: a longitudinal study based on job advertisements. Production, 27(spe). http://doi.org/10.1590/0103-6513.229916

Nitkiewicz, T., \& Ayen, Z. (2018). Identifying key criteria in development of Industrial Engineering education. MATEC Web of Conferences, 183, 04008. http://doi.org/10.1051/matecconf/201818304008

Pine, B. J., \& Gilmore, J. H. (1998). Welcome to the experience economy. Harvard Business Review, 76(4), 97-105. Retrieved from https://hbr.org/1998/07/welcometo-the-experience-economy

Prifti, L., Knigge, M., Kienegger, H., \& Krcmar, H. (2017). A Competency Model for "Industrie 4.0" Employees. In Proceedings der 13. Internationalen Tagung Wirtschaftsinformatik (WI 2017) (pp. 46-60). St. Gallen. Retrieved from https://www.wi2017.ch/images/wi2017-0262.pdf

Ślusarczyk, B. (2018). Industry 4.0 - Are We Ready? Polish Journal of Management Studies, 17(1), 232-248. http://doi.org/10.17512/pjms.2018.17.1.19

Ulewicz, R. (2013). System Approach To Assure Quality of Education At the Faculty of Management of Czestochowa University of Technology. Polish Journal of Management Studies, 8, 259-268.

Wahlster, W., Helbig, J., Hellinger, A., Stumpf, M. A. V., Blasco, J., Galloway, H., \& Gestaltung, H. (2013). Securing the future of German manufacturing industry. Recommendations for implementing the strategic initiative INDUSTRIE 4.0. Retrieved from

http://www.acatech.de/fileadmin/user_upload/Baumstruktur_nach_Website/Acatech/ro ot/de/Material_fuer_Sonderseiten/Industrie_4.0/Final_report_Industrie_4.0_acces sible.pdf

Wiśniewska-Sałek, A. (2018). Sustainable Development in Accordance With the Concept of Industry 4.0 on the Example of the Furniture Industry. MATEC Web of Conferences, 183, 04005. http://doi.org/10.1051/matecconf/201818304005 